\title{
Kendi kendine bağlanabilen akışkan bir kompozit rezinin yüzeyel Sınıf I kavitelerde klinik performansının değerlendirilmesi
}

\author{
Fatma Dilşad Öz(0000-0002-7450-723X) ${ }^{\alpha}$, Esra Ergin(0000-0002-7667-7494) ${ }^{\alpha}$, Filiz Yalçın Çakır(0000-0002-7972-5391) ${ }^{\alpha}$, \\ Sevil Gürgan(0000-0002-0408-8949) ${ }^{\alpha}$
}

Selcuk Dent J, 2020; 7: 286-293 (Doi: 10.15311/selcukdentj.467890)

Başvuru Tarihi: 06 Ekim 2018 Yayına Kabul Tarihi: 03 Ekim 2019

\section{öz}

\section{Kendi kendine bağlanabilen akışkan bir kompozit rezinin yüzeyel Sınıf I kavitelerde klinik performansının değerlendirilmesi}

Amaç: Bu çalışmanın amacı kendi kendine bağlanabilen bir akışkan kompozit rezini geleneksel bir kompozit rezin ile karşılaştırarak Sınıf I kavitelerdeki klinik performansını değerlendirmektir.

Gereç ve Yöntem: Yirmibeş hastaya, her hastada en az 2 adet Sınıf I restorasyon yerleştirildi $(n=65)$. Kaviteler hazırlandıktan sonra rastgele seçim yapılarak ya kendi kendine bağlanabilen akışkan bir kompozit Vertise Flow/Kerr-VR) [Grup-1 $(n=33)$ ], ya da etch\&rinse bir adeziv kullanılarak geleneksel bir akışkan kompozit (Luxa/DMG-LX) [Group-2 $(n=32)$ ] uygulandı. Restorasyonlar uygulandıktan 1 hafta sonra (başlangıç) ve 4 yıl boyunca FDI kriterlerine göre değerlendirildi. İstatistiksel analizler Ki-kare testi ve Cochran Q-testini takiben Mc Nemar's testleri ile yapıldı $(p=0.05)$.

Bulgular: Dört yıl sonunda 49 restorasyon değerlendirildi. Hastaların kontrollere gelme oranı $\% 72$ idi. Dört yılın sonunda 3 adet VR (\%11.5) ve 2 adet LX (\%7.6) restorasyon kaybedildi. 17 adet VR (\%73.9) ve 14 adet LX (\%58.3) restorasyon kenar uyumu açısından klinik olarak iyi (skor 2) şeklinde skorlandı $(p>0.05)$. Restorasyonlar kenar renklenmesi açısından değerlendirildiğinde ise, VR restorasyonların \%39.1'i ve LX restorasyonlarının \%25'i klinik olarak iyi (skor 2) şeklinde skorlandı $(p>0.05)$. Restorasyonların hiçbirinde ikincil çürük ya da postoperatif duyarlıık görülmedi. Başlangıç ile karşılaştıııldığında; 4 yıl sonunda VR ve LX akışkan kompozit rezinlerde kenar uyumu ve kenar renklenmesi açısından anlamlı farklılıklar görüldü $(p<0.001)$.

Sonuç: Her iki akışkan kompozit rezin de dört yılın sonunda yüzeyel sınıf I kavitelerde benzer ve klinik olarak kabul edilebilir sonuçlar göstermiştir.

\section{ANAHTAR KELIMELER}

Akışkan kompozit, dental adezivler, diş kavite preparasyonu, okluzal

Arka bölgedeki dişlerin okluzal yüzeyleri morfolojileri nedeniyle çürüğe yatkın bölgeler olarak bilinmektedir. Fissürlerde çürüğün sık görülmesi, fissür örtücü uygulamalarını koruyucu bir yaklaşım olarak popüler hale getirmiştir. ${ }^{1,2}$ Günlük diş firçalama ve topikal florür uygulamaları gibi koruyucu yaklaşımların çürük

\section{ABSTRACT}

Evaluation of the clinical performance of a self-adhering composite resin in Class I cavities

Background: The aim of this study was to evaluate long-term clinical performance of a self-adhering flowable resin composite in comparison with a conventional flowable resin composite used with an etch\&rinse adhesive system on minimally invasive Class I cavities.

Materials and Methods: Twenty-five patients received at least one pair of Class I restorations $(n=65)$. After class I cavities were prepared they were randomly restored either with a self-adhering flowable resin composite (VertiseFlow/Kerr-VR) [Group-1 $(n=33)$ ], or with a flowable resin composite (Luxaflow/DMG-LX) in combination with an etch\&rinse adhesive system (Teco/DMG) [Group-2 $(n=32)]$ according to the manufacturers' instructions. Restorations were evaluated at baseline and yearly for 4 years according to FDI criteria by two evaluaters. Statistical analysis was carried out with Pearson Chi-Square test and Cochran Q-test followed by Mc Nemar's tests $(p=0.05)$.

Results: After 4 years a total of 49 restorations were evaluated with a recall rate of $72 \%$. At 4 -year, 3 (11.5\%) VR and 2 LX (7.6\%) restorations exhibited cumulative retention lost. 17 (73.9\%) VR and 14 LX (58.3\%) restorations exhibited clinically good (2) score for marginal adaptation. At 4-year evaluations VR and LX showed similar results regarding all evaluated criteria $(p>0.05)$. None of the restorations demonstrated secondary caries and post operative sensitivity. Both materials showed significant changes at 4 years regarding marginal staining when compared to baseline $(p<0.001)$. Furthermore, significant changes were observed for VR and $L X$ at 1 , 2,3 and 4 years for marginal adaptation according to baseline $(p<0.001)$.

Conclusion: The use of both materials for the restoration of Class-I cavities showed a similar and clinically acceptable performance at the end of 4-year.

\section{KEYWORDS}

Flowable composite resin, occlusal, dental cavity preparation, dental adhesives

önlenmesinde etkisi bulunurken, fissürlerin fissür örtücülerle kapatıması daha etkili olabilmektedir. ${ }^{3}$ Fissür çürüklerinin önlenmesinde cam iyonomerler, kompomerler, rezin bazlı fissür örtücüler ve akışkan kompozitler gibi çeşitli örtücü materyaller kullanılmaktadır. ${ }^{4,5}$

\footnotetext{
${ }^{\alpha}$ Hacettepe Üniversitesi Diş Hekimliği Fakültesi Restoratif Diş Tedavisi Anabilim Dalı, Ankara, Türkiye
} 
Akışkan kompozit rezinler, pek çok kavite tipinde kullanılmaktadır. ${ }^{1,3,5}$ Akışkan kompozit rezinlerin yapılarındaki gelişmeler ile Sını । kavitelere uygulanması da artış göstermiştir. Akışkan kompozitler Sınıf V kavitelerde ve Sınıf II kavitelerde restorasyonların altında kuvvet kırıcı olarak sıklıkla tercih edilmektedirler. ${ }^{6,7}$ Düşük viskoziteye ve elastisite modülüne sahip olmaları ve kullanım kolaylıkları tercih edilme nedenleri arasındadır. ${ }^{8}$ Akışkan kompozit rezinlerin doldurucu içerikleri (hacimce \%37-53), geleneksel kompozitlerden (hacimce \%50-70) daha düşüktür. Materyallerin visköziteleri, farklı doldurucu içeriklerinden etkilenmiştir. Aynı zamanda, fissür örtücülerden daha yüksek doldurucu içeriğine sahiptirler ve pek çok farklı renkleri bulunduğundan estetik materyallerdir. Bundan dolayı akışkan kompozitler Sınıf I, II ve V kavitelerde yaygın olarak kullanılmaktadır. ${ }^{8}$ Akışkan yapılarından dolayı şıııngalar içerisinde paketlenmeleri küçük kavitelere uygulama

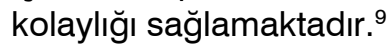

Adeziv sistemlerin uygulama süreleri üretici firma talimatlarına göre birbirlerinden farkllık göstermektedir. Bunun yanısıra, "etch\&rinse" uygulama sistemlerinde uygulama aşamaları "self-etch" adezivlere göre fazladır. Üreticiler uygulama basamaklarını azaltmak için kendiliğinden bağlanabilen bir akışkan kompozit sistemi (Vertise Flow, Kerr, Orange, CA, ABD) geliştirmişlerdir. Vertise Flow'un üreticileri daha kısa uygulama süresi ile küçük Sınıf I kavitelere restoratif materyal olarak, Sınıf I ve II kavitelere ise kaide materyali olarak uygulanabilir olduğunu bildirmişlerdir. Vertise Flow ile kısa süreli klinik çalışmalar rapor edilmiştir, ${ }^{10,11}$ ancak uzun dönem sonuçlar henüz yoktur. $\mathrm{Bu}$ çalışmanın amacı kendiliğinden bağlanabilen bir akışkan kompozit olan Vertise Flow'un 4 yıllık klinik performansını geleneksel bir kompozit rezin (LuxaFlow) ile karşılaştırarak değerlendirmektir. Test edilen sıfır hipotezi yüzeyel Sınıf I kavitelere yerleştirilen iki akışkan kompozit rezin arasında anlamlı bir fark olmayacağıdır.

\section{GEREÇ VE YÖNTEM}

Hacettepe Diş Hekimliği Fakültesi Restoratif Diş Tedavisi Anabilim Dalı'ndaki hastalar arasından yaş ortalamaları 20 olan 25 hasta (18-25 arası) seçildi. Dahil edilme kriterleri şu şekildeydi: (1) hastanın 18 yaşında ya da daha büyük olması, (2) tıbbi ya da davranışsal bir problemi olmaması, (3) ağzında en az 28 diş bulunması idi. Dahil edilmeme kriterleri ise (1) kötü ağız hijyeni, (2) kontrol edilemeyen her tarafa yayılan çürüklere sahip olma, (3) bruksizm, (4) hareketli kısmi protez kullanma, (5) kserostomi idi. Kriterlere uyan hastaların muayeneleri ağız aynası ve sond kullanarak gerçekleştirildi ve restorasyon gerektiren dişler tespit edildi. Radyolojik ve klinik muayeneler sonrasında dişlerin vitalitesi kontrol edildi ve yüzeysel Sınıf I kaviteler çalışmaya dahil edildi. Restorasyonlar için dahil edilme kriterleri: (1) doğal ya da kronlanmış karşıt dişi bulunması, (2) kavitelerin minumun $1.5 \mathrm{~mm}$ ve maksimum $2 \mathrm{~mm}$ derinliğinin olması, (3) okluzal pit ve fissürlerle sınırlanmış olması, (4) daha önce restore edilmemiş olması, (5) kasplar arası mesafenin 1/3'ünü geçmeyecek büyüklükte olması. Restorasyonlar için dahil edilmeme kriterleri: (1) vital olmayan ya da daha önce kanal tedavisi uygulanmış dişler, (2) pulpal ya da periapikal patolojisi olan dişler, (3) tedavi öncesinde alınan radyograflarda pulpa ekspozuna neden olabilecek çürük görülmesi.

\section{Restoratif işlemler}

Restoratif işlemler öncesinde tüm fissürler, mikromotorla beyaz lastik kullanılarak temizlendi ve yıkandı. Preparasyonun boyutu çürüğün büyüklüğüne göre belirlendi ve yükseklik olarak 2 mm'den büyük kaviteler çalışmaya dahil edilmedi. Tüm dahil edilen fissür çürükleri dentin dokusuna ulaşmışlardı. Restorasyonlar, iki deneyimli diş hekimi tarafından gerçekleştirdi. Randomizasyon, restoratif materyal seçilirken diş numarasına göre yazı-tura atarak belirlendi.

Çalışmada kullanılan materyaller Tablo 1'de gösterildi. Çalışmaya sadece molar dişler dahil edildi. Kaviteler elmas fissür frezler (Diatech, Coltane/Whaledent AG, Altstaetten, İsviçre, 0211714) kullanılarak yüksek hızda aeratör ile hazırlandı. Çürüğün temizlenmesi ise, mikromotor ile çelik ront frezler (Edenta, Liechtenstein, D02.001) kullanılarak tamamlandı. Hastalar restoratif işlemler sırasında ağrı hissettiğinde, ya da duyarlılık oluştuğunda lokal anestezi uygulandı. Dentin dokusu, sondalamada sert olarak hissedildiğinde ise daha fazla doku kaldırımadı.

Vertise Flow (VR) $(n=33)$ : Kavite preparasyonu rulo pamuklar kullanılarak izole edildikten sonra Vertise Flow tüm kaviteye yerleştirildi. Kendi özel fırçası kullanılarak hafif basınç ile 15-20 saniye uygulandı ve ince bir tabaka $(<0.5 \mathrm{~mm})$ elde edildi. Fazlalıklar fırça ile kaldırıldı ve bu ince tabaka 20 saniye ışıkla polimerize edildi (Radii Plus, SDI, Viktorya, Avustralya). Sonrasında Vertise Flow $2 \mathrm{~mm}$ ya da daha ince tabakalar halinde kaviteye uygulandı. Her tabaka 20 saniye ışıkla polimerize edildi.

Luxa Flow (LX) $(n=32)$ : Kavite preparasyonu rulo pamuklar kullanılarak izole edildi ve mine 30 saniye, dentin ise 15 saniye \%37'lik fosforik asit (Total Etch, Ivoclar Vivadent, Schaan, Liechtenstein) ile pürüzlendirildi. Sonrasında, yıkandı ve kavite hafifçe kurutuldu. Daha sonra adeziv (Teco, DMG, Hamburg, Almanya) yüzeye mikrofırça kullanılarak 15 saniye boyunca uygulandı. Adeziv hafifçe kurutuldu ve 10 saniye ışıkla polimerize edildi. Sonrasında Luxa Flow tüm kaviteye $2 \mathrm{~mm}$ ya da daha ince tabakalar halinde yerleştirildi ve ışıkla polimerize edildi. 
Tablo 1.

\section{Çalışmada kullanılan materyaller}

\begin{tabular}{|c|c|c|c|}
\hline $\begin{array}{l}\text { Materyal } \\
\text { /Üretici }\end{array}$ & Seri no & İçerik & Uygulama \\
\hline $\begin{array}{l}\text { Vertise Flow / } \\
\text { Kerr, Orange, } \\
\text { ABD }\end{array}$ & 3413043 & $\begin{array}{l}\text { GPDM adheziv monomer, } \\
\text { UDMA, BisGMA, ve diğer } \\
\text { metakrilat komonomerleri, } \\
\text { foto-başlatıcılar, ağrlıkça } \\
\% 70 \text { doldurucu. Ytterbiyum } \\
\text { florid, baryum } \\
\text { aluminosilikat cam, } \\
\text { prepolimerize } \\
\text { doldurucular, ve kollodial } \\
\text { silika }\end{array}$ & $\begin{array}{l}\text { Vertise Flow kavitenin içine } \\
\text { şıınga ile enjekte edilir. Ardından } \\
\text { kendi özel fırçası ile } 15-20 \text { saniye } \\
\text { tüm kaviteye adapte edilir ve ince } \\
\text { bir tabaka elde edilir (<0.5 mm). } \\
\text { Kenarlardaki fazlalıklar } \\
\text { uzaklaştıııı ve } 20 \text { saniye ışıkla } \\
\text { polimerize edilir Sonrasında } \\
\text { Vertise Flow } 2 \text { mm ya da daha } \\
\text { ince tabakalar halinde kaviteye } \\
\text { uygulanır. Her tabaka } 20 \text { saniye } \\
\text { ışıkla polimerize edilir. }\end{array}$ \\
\hline $\begin{array}{l}\text { Luxa Flow / } \\
\text { DMG, } \\
\text { Hamburg, } \\
\text { Almanya }\end{array}$ & 620342 & $\begin{array}{l}\text { BIS-GMA, cam ve ağırlıkça } \\
\% 63 \text { doldurucu }\end{array}$ & $\begin{array}{l}2 \mathrm{~mm} \text { ya da daha ince tabakalar } \\
\text { halinde kaviteye uygulanır. Her } \\
\text { tabaka } 20 \text { saniye ışıkla polimerize } \\
\text { edilir. }\end{array}$ \\
\hline
\end{tabular}

Kullanılan ışık cihazının ışık gücü polimerizasyon öncesi 1200 $\mathrm{mW} / \mathrm{cm}^{2}$ olacak şekilde kontrol edildi. Restorasyonların okluzyonları artikülasyon kağıdı kullanarak kontrol edildi ve daha sonra bitirme ve polisaj işlemleri ince elmas bitirme frezleri ve lastik uçlar (Kerr Corporation, Orange, CA, ABD) kullanılarak yapıldı.

\section{Klinik değerlendirme}

Hastalar restorasyonlar yerleştirildikten 1 hafta sonra (başlangıç) ve $1,2,3$ ve 4 yıl sonra kontrole çağıııldı. Restorasyonlar, retansiyon, kenar uyumu, kenar renklenmesi, yüzey parlaklığı, renk uyumu, ikincil çürük ve postoperatif duyarlılık açısından FDI kriterleri kullanılarak değerlendirildi. ${ }^{12}$ Skorlar şu şekildeydi: (1) Klinik olarak mükemmel/çok iyi, (2) Klinik olarak iyi, (3) Klinik olarak yeterli/tatminkar, (4) Klinik olarak yetersiz ve (5) Klinik olarak kötü. Kalibrasyon (araştırmacılar arası uyum) için her skoru temsil eden 10 fotoğraf kullanıldı. Çalışmaya başlamadan önce, araştırmacılar arası ve araştırmacıların kendi içinde uyumun en az \%85 olması gerekliydi ve bu 10 fotoğraf kullanılarak kalibrasyon sağlandı. Kontrol randevularında restorasyonları uygulamayan, çalışma protokolünü bilmeyen iki deneyimli ve yukarıda belirtilen şekilde kalibre olmuş araştırmacı ayrı ayrı ağız aynası, sond ve hava-su spreyi kullanarak restorasyonları değerlendirdi. Farklı görüşlerin olduğu durumlarda muayeneler sırasında değerlendirme yapıldı. Araştırmacılar hastalar klinikten ayrımadan önce ortak bir karar aldılar. Değerlendirme formları araştırmacılar tarafından dolduruldu ancak grupları bilmemekteydiler.

Restorasyonların yıllar içindeki kümülatif retansiyon oranları şu denklemle hesaplandı (ADA Rehberi, 2001) 13,14: Kümülatif başarısızılı $=[(\mathrm{PF}+\mathrm{NF}) /(\mathrm{PF}+\mathrm{RR})] \times 100 . \mathrm{PF}$ daha önce kaybedilmiş restorasyonlar; NF hastanın çağııııı değerlendirildiği seansta görülen yeni kaybedilmiş restorasyonların sayısı; RR değerlendirme yapılan seansta değerlendirilmiş tüm restorasyonların sayısı.

İstatistiksel analizler IBM SPSS 22.0 (SPSS, Chicago, IL, ABD) programı kullanılarak yapıldı. İki restoratif materyali karşılaştırmak ve değerlendirilen kriterler açısından dağılımları tespit etmek için Pearson ki-kare testi kullanıldı. Yıllar içinde materyeller arasında farklılıklar tespit edildiğinden her restoratif materyalin farklı zaman noktaları arasındaki değişimler Cochran Q-testi ile analiz edildi. Kenar uyumu, kenar renklenmesi ve renk uyumu skorlarının başlangıçtan itibaren zaman içindeki değişimini belirlemek için Mc Nemar's testi kullanıldı. Anlamlılık derecesi $p<0.05$ olarak belirlendi.

\section{BULGULAR}

Hastaların kontrollere gelme oranı 4 yılın sonunda \%72 idi. Restorasyonlardan hiçbiri postoperatif duyarllık ve ikincil çürüğe neden olmadı (Tablo 2).

\section{Retansiyon}

Retansiyon oranları her iki materyal için 1 yilın sonunda \%100'dü. İkinci yılın sonunda 2 adet VR ve 1 adet LX restorasyon kaybedildi. Üçüncü yılda retansiyon kaybı olmadı ancak, 4. yılda 1 adet VR ve 1 adet LX restorasyon kaybedildi. Dördüncü yılın sonunda kümülatif retansiyon kaybı VR için \% 11.5 ve LX için \%7.6 idi (Tablo 3).

\section{Kenar uyumu}

Bir yıllık değerlendirmede 13 adet VR (\%41.9) ve 11 adet LX (\%37.5) restorasyon minör kenar uyumsuzlukları gösterdi ve klinik olarak iyi (skor 2) olarak skorlandı. 2 yıllık değerlendirmelerde 16 adet VR (\%64) restorasyon ve 14 adet LX (\%53.8) restorasyon klinik olarak iyi (skor 2) olarak skorlandı $(p>0.05)$ ve sadece 1 adet VR restorasyon klinik olarak kötü (skor 5) skoru aldı. 3 yıllık kontrollerde 16 adet VR (\%64) ve 14 adet LX (\%53.8) restorasyon klinik olarak iyi (skor 2) olarak skorlandı $(p>0.05) .4$ yılın sonunda ise 17 adet VR (\%73.9) restorasyonu 14 adet LX (\%53.3) restorasyonu klinik olarak iyi (skor 2) skoru aldı $(p>0.05)$. 
Tablo 2.

\section{Restorasyonların klinik sonuçları}

\begin{tabular}{|c|c|c|c|c|c|c|c|c|c|c|c|c|}
\hline \multirow{2}{*}{\multicolumn{2}{|c|}{$\begin{array}{l}\text { Değerlendirme } \\
\text { Kriteri }\end{array}$}} & \multirow[b]{2}{*}{ Skor } & \multicolumn{2}{|c|}{ Başlangıç $n(\%)$} & \multicolumn{2}{|c|}{1 yil n(\%) } & \multicolumn{2}{|c|}{2 yıl n(\%) } & \multicolumn{2}{|c|}{3 yıl n(\%) } & \multicolumn{2}{|c|}{4 yıl n(\%) } \\
\hline & & & VR (33) & LX (32) & VR (31) & LX (31) & VR (27) & LX (27) & VR (25) & LX (26) & VR (24) & $\begin{array}{c}\text { LX } \\
\text { (25) }\end{array}$ \\
\hline \multirow{15}{*}{ 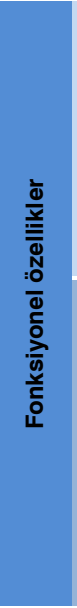 } & \multirow{7}{*}{ 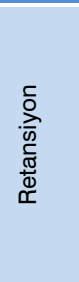 } & 1 & 33 & 32 & 31 & 31 & 25 & 26 & 25 & 26 & 23 & 24 \\
\hline & & & $(100)$ & $(100)$ & $(100)$ & $(100)$ & (92.6) & (96.3) & $(100)$ & $(100)$ & (95.8) & (96) \\
\hline & & 2 & & & & & & & & & & \\
\hline & & 3 & & & & & & & & & & \\
\hline & & 4 & & & & & & & & & & \\
\hline & & 5 & & & & & 2 & 1 & & & 1 & 1 \\
\hline & & & & & & & (7.4) & (3.7) & & & $(4.2)$ & (4) \\
\hline & \multirow{8}{*}{ 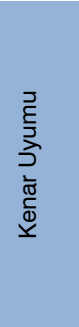 } & 1 & 33 & 32 & 18 & 20 & 9 & 12 & 9 & 12 & 6 & 10 \\
\hline & & & $(100)$ & $(100)$ & $(58.1)$ & (62.5) & (36.0) & $(46.2)$ & $(36.0)$ & $(46.2)$ & (26.1) & $(41.7)$ \\
\hline & & 2 & & & $13^{s}$ & $11^{\mathrm{s}}$ & $16^{\mathrm{s}}$ & $14^{\mathrm{s}}$ & $16^{\mathrm{s}}$ & $14^{\mathrm{S}}$ & $17^{\mathrm{S}}$ & $14^{\mathrm{s}}$ \\
\hline & & & & & (41.9) & (37.5) & $(64.0)$ & (53.8) & $(64.0)$ & (53.8) & (73.9) & (58.3) \\
\hline & & 3 & & & & & & & & & & \\
\hline & & 4 & & & & & & & & & & \\
\hline & & 5 & & & & & 1 & & & & & \\
\hline & & & & & & & (3.8) & & & & & \\
\hline \multirow{22}{*}{ 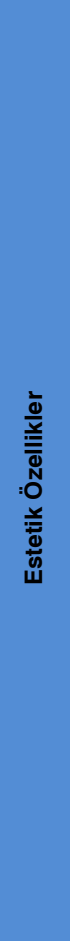 } & \multirow{8}{*}{ 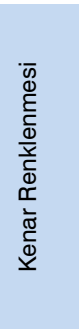 } & 1 & 33 & 32 & 25 & 26 & 16 & 20 & 16 & 20 & 14 & 18 \\
\hline & & & (100) & (100) & (80.6) & (83.9) & $(64.0)$ & (76.9) & $(64.0)$ & (76.9) & $(60.9)$ & (75.0) \\
\hline & & 2 & & & 5 & 3 & 9 & 6 & 9 & 6 & $9^{S}$ & $6^{5}$ \\
\hline & & & & & (16.1) & (9.7) & (36.0) & (23.1) & $(36.0)$ & (23.1) & (39.1) & (25.0) \\
\hline & & 3 & & & & & & & & & & \\
\hline & & 4 & & & & & & & & & & \\
\hline & & 5 & & & 1 & 2 & & & & & & \\
\hline & & & & & (3.2) & (6.5) & & & & & & \\
\hline & \multirow{7}{*}{ 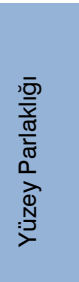 } & 1 & 33 & 32 & 31 & 29 & 23 & 24 & 23 & 24 & 21 & 22 \\
\hline & & & (100) & (100) & (100) & (93.5) & (92.0) & (92.3) & (92.0) & (92.3) & (91.3) & (91.7) \\
\hline & & 2 & & & & 2 & 2 & 2 & 2 & 2 & 2 & 2 \\
\hline & & & & & & (6.5) & (8.0) & (7.7) & (8.0) & (7.7) & (8.7) & (8.3) \\
\hline & & 3 & & & & & & & & & & \\
\hline & & 4 & & & & & & & & & & \\
\hline & & 5 & & & & & & & & & & \\
\hline & \multirow{7}{*}{ 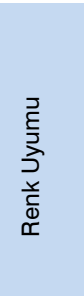 } & 1 & 33 & 32 & 28 & 28 & 20 & 23 & 20 & 23 & 18 & 21 \\
\hline & & & (100) & (100) & $(90.3)$ & (90.3) & $(80.0)$ & (88.5) & $(80.0)$ & (88.5) & (78.3) & (87.5) \\
\hline & & 2 & & & 3 & 3 & 5 & 3 & 5 & 3 & $5^{s}$ & 3 \\
\hline & & & & & (9.7) & (9.7) & (20.0) & (11.5) & (20.0) & (11.5) & (21.7) & (12.5) \\
\hline & & 3 & & & & & & & & & & \\
\hline & & 4 & & & & & & & & & & \\
\hline & & 5 & & & & & & & & & & \\
\hline \multirow{12}{*}{ 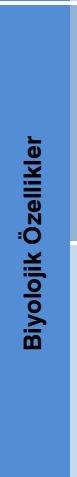 } & \multirow{6}{*}{ 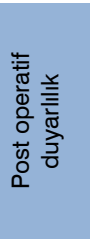 } & 1 & 32 & 32 & 31 & 31 & 27 & 27 & 27 & 27 & 24 & 25 \\
\hline & & & (100) & (100) & (100) & (100) & (100) & (100) & (100) & (100) & (100) & (100) \\
\hline & & 2 & & & & & & & & & & \\
\hline & & 3 & & & & & & & & & & \\
\hline & & 4 & & & & & & & & & & \\
\hline & & 5 & & & & & & & & & & \\
\hline & \multirow{6}{*}{ 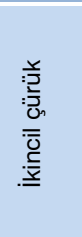 } & 1 & 32 & 32 & 31 & 31 & 27 & 27 & 27 & 27 & 24 & 25 \\
\hline & & & (100) & (100) & (100) & (100) & $(100)$ & (100) & (100) & (100) & (100) & (100) \\
\hline & & 2 & & & & & & & & & & \\
\hline & & 3 & & & & & & & & & & \\
\hline & & 4 & & & & & & & & & & \\
\hline & & 5 & & & & & & & & & & \\
\hline
\end{tabular}

$s$ Cochran's $Q$ testini takiben yapılan McNemar's testi, başlangıca göre anlamlı farklılı gösterdiğini belirtmektedir $(p<0.05)$

VR: Vertise Flow, LX: Luxa Flow 
Tablo 3.

\section{Kaybedilen restorasyon sayısının 4 yıl} içindeki kümülatif dağılımı (\%)

\begin{tabular}{|lccc|} 
& 2 yıl & 3 yıl & 4 yıl \\
\hline Vertise Flow & 7.4 & 7.4 & 11.5 \\
\hline LuxaFlow & 3.7 & 3.7 & 7.6 \\
\hline
\end{tabular}

Cochran's Q testine göre başlangıç ile karşılaştırıldı̆̆ında gruplarda anlamlı bir değişim gözlenmemiştir. $(p<0.05)$.

\section{Kenar renklenmesi}

Bir yıllık değerlendirmede 5 adet VR (\%16.1) ve 3 adet LX (\%9.7) restorasyon minör kenar renklenmesi gösterdi ve klinik olarak iyi (skor 2) şeklinde skorlandı. 1 adet VR (\%3.2) ve 2 adet LX (\%6.5) klinik olarak kötü (skor 5) şeklinde skorlandı. İki yıllık kontrollerde, 9 adet VR (\%36) ve 6 adet LX (\%23.1) restorasyon klinik olarak iyi (skor 2) şeklinde skorlandı. Dört yılın sonunda 14 adet VR (\%60.9) ve 18 adet LX (\%75) restorasyon klinik olarak çok iyi (skor 1) şeklinde skorlandı $(p>0.05)$.

\section{Yüzey parlaklığı}

1 yılın sonunda, tüm VR restorasyonlar klinik olarak çok iyi (skor 1) olarak skorlanırken, 2 adet LX (\%6.5) restorasyonu klinik olarak iyi (skor 2) olarak skorlandı. 2 yıllık değerlendirmede, 2 adet VR (\%7.7) ve 2 adet LX (\%7.7) restorasyonu klinik olarak iyi (skor 2) şeklinde skorlandı. Dört yılın sonunda ise, her iki grupta da restorasyonların çoğu [VR:\%91.3, LX:\%91.7] klinik olarak çok iyi (skor 1) şeklinde skorlandı $(p>0.05)$.

\section{Renk uyumu}

3 adet $V R$ ve 3 adet LX restorasyonu 1 yıllık değerlendirmede klinik olarak iyi (skor 2) şeklinde skorlandı. 2 yıllık kontrollerde 5 adet VR (\%20) ve 3 adet LX (\%11.5) restorasyon klinik olarak iyi (skor 2) şeklinde skorlandı. 4 yılın sonunda 5 adet VR (\%21.7), 3 adet LX (\%12.5) restorasyon klinik olarak iyi (skor 2) şeklinde skorlandı $(p>0.05)$.

Pearson Ki-kare testi sonuçlarına göre VR ve LX grupları arasında kriterlerin hiçbirinde anlamlı bir farklılık görülmemiştir $(p>0.05)$. Mc Nemar's testleri kenar uyumu açısından VR ve $L X$ gruplarında tüm değerlendirme zamanlarında (1, 2, 3 ve 4 yıl) başlangıca göre istatistiksel olarak anlamlı farklılık gösterdi $(p<0.001)$. Bunun yanında, her iki materyel de 4 yıllık değerlendirme sonunda kenar renklenmesi açısından başlangıca göre istatistiksel olarak anlamlı farklılık gösterdi $(p<0.001)$. Kenar uyumu açısından incelendiğinde ise 4 yılın sonunda VR grubu başlangıca göre istatistiksel olarak anlamlı farklılık gösterdi $(p<0.001)$.

\section{TARTISSMA}

Bu klinik çalışmada 4 yılın sonunda her iki materyalin de klinik olarak kabul edilebilir olduğu bulunmuştur. Çalışmanın hipotezi kabul edilmiştir. İncelenen kriterlerde birbirleri arasında farklılık bulunmayan materyallerin her ikisi de yıllar içerisinde kenar renklenmesi ve kenar uyumu açısından klinik olarak kabul edilebilir değişimler göstermiştir.

Yüzeyel okluzal restorasyonlar ile ilgili klinik çalışmalar genellikle çocuklar üzerinde yapılmaktadır ve genellikle uygulamayı gerçekleştirirken mineye bağlanmayı sağlamak daha zor olabilmektedir. Aynı zamanda ebeveynlerin çocuklarını kontrol seanslarına getirmeleri gerekeceğinden hastaları takip etmek de güç olmaktadır. Bu çalışmada 18 yaşından büyük katılımcılar tercih edilmiştir. Böylece kontrol randevularına gelme oranının da daha iyi olacağı düşünülmüştür. Kontrol randevularına gelme oranı 4 yılın sonunda \%72'dir.

Vertise Flow, bir self-etch adeziv sistemi ile birleştirerek üretilmiş akışkan bir kompozittir. Kompozitin bağlanma mekanizması gliserofosfat dimetakrilat (GPDM) aracılığıyla, GPDM monomerinin fonksiyonel fosfat grupları ve mine ile dentinin kalsiyum iyonları arasında kimyasal bir bağ kurarak gerçekleşmektedir. ${ }^{15}$ Vertise Flow'un üreticileri restoratif uygulamaların basamaklarını azaltmak için, kendi kendine bağlanabilen bu akışkan kompozit rezini, primer ve bond ajanları ile birleştirilerek geliştirilmiştir. Özellikle davranışsal problemleri olan genç hastalarda ve çocuklarda çoklu aşamaların kaldırımasına, daha kolay uygulamalara ve uygulama süresinin azaltılmasına gerek duyulmaktadır.

Adezivlerin uygulama kolaylıkları mine ve dentine iyi bir bağlanma elde edilebilmesi açısından önemlidir. Vertise Flow'un mine ve dentine bağlanma dayanıklılığının değerlendirildiği in vitro bir çalışmada, Vertise Flow'un, 5 farklı tek şişe self-etch adezivin kendi akışkan kompozitleri ile kullanıldığında (G-Bond/Gradia Direct LoFlo (GC, Tokyo, Japonya) AdheSE One/Tetric Evo Flow (Ivoclar Vivadent, Schaan, Liechtenstein), Adper Easy Bond/Filtek Supreme XT Flow (3M ESPE, St. Paul, MN, USA), XenoV/X Flow (Dentslpy Detrey, Kostanz, Almanya), iBOND/Venus Flow (Heraeus Kulzer, Hanau, Almanya) tüm bu sistemlerden daha düşük bağlanma dayanıklılığ değerleri gösterdiği tespit edilmiştir. ${ }^{11}$ Bununla birlikte, Vertise Flow ile ilgili yayınlanan ilk klinik çalışmanın 6 aylık sonuçlarında Vertise Flow restorasyonların hiçbirinin kaybedilmediği rapor edilmiştir. ${ }^{16}$ Benzer bir şekilde, bu çalışmada da bir yıl sonunda kaybedilen restorasyon bulunmamaktadır. Ancak 4 yıl sonra, 3 adet Vertise Flow restorasyon kaybedilmiştir. Başka bir klinik çalışma, Vertise Flow'u, 2 farklı fissür örtücü ve başka bir akışkan kompozit ile karşılaştırmıştır. ${ }^{10} \mathrm{Bu}$ çalışmada diğer akışkan kompozit rezin (Tetric EvoFlow, Ivoclar Vivadent), bir adeziv sistem ile kombine kullanılmış ve Vertise Flow ile fissür örtücülere (Fissurit FX, Grandio Seal) göre daha iyi retansiyon oranı göstermiştir. İki yıl sonra en düşük retansiyon oranı ise Vertise Flow'da görülmüştür. ${ }^{10}$ Bizim çalışmamızda ise Vertise Flow ve bir adeziv sistem ile kombine kullanılan Luxa Flow benzer klinik sonuçlar göstermiştir. 
FDI kriterlerinin, klinik incelemelerde USPHS kriterlerine göre daha hassas sonuç verdiği rapor edilmektedir. ${ }^{12}$ Küçük farklılıkların olduğu restorasyonlar, FDI kriterlerinde mükemmel restorasyonlardan farklı skorlanmaktadır. Bu durum, dört yıllık değerlendirme sonunda kenar uyumu ve kenar renklenmesi açısından yüksek skor 2 oranını açıklamaktadır. Kitasako ve ark. ${ }^{17}$ iki farklı tip akışkan kompozit rezini iki aşamalı bir selfetch adeziv ile uygulayarak FDI kriterlerine göre karşılaştırmışlar ve test edilen grupların 3 yılın sonunda bizim çalışmamı ile benzer klinik sonuçları olduğunu göstermişlerdir.

Self-etch adezivlerin kompozit rezinlere eklenmesi materyallerin fiziksel özelliklerini etkileyebilir. Kompozit rezinlerin içindeki hidrofilik monomerler kendi kendine bağlanan materyallerde stabil olmayan boyutlara neden olmaktadır. ${ }^{18}$ Klinik çalışmalar, etch\&rinse adezivlerle karşılaştırıldığında self-etch adezivlerin uzun dönem sonuçlarının daha kuşkulu sonuçlar ortaya koyduğunu göstermektedir. ${ }^{19-21}$ Ancak, bu klinik çalışmada self-etch sistemle bağlanan restoratif materyal, etch\&rinse sistemle bağlanan restoratif sistem ile benzer sonuç göstermiştir. Ayrıca, içerik açısından materyeller incelendiğinde, Vertise Flow (\%70) ve LuxaFlow'un (\%63) doldurucu içerikleri üretici bilgilerine göre ağırlıkça benzerdir. Bu nedenle fiziksel ve mekanik özelliklerinin birbirine yakın olması beklenmektedir. Akışkan kompozitlerde, geleneksel kompozitlere göre daha çok polimerizasyon büzülmesi olduğu düşünülmektedir. ${ }^{22}$ Sonuç olarak, daha yüksek oranda kenar uyumu bozulması, kenar renklenmesi ve ikincil çürük beklenmektedir. Ancak, Lawson ve ark. ${ }^{23} 2$ yılın sonunda akışkan kompozitlerin geleneksel kompozitlerle benzer sonuçlar gösterdiğini rapor etmiştir. Bizim çalışmamızda da, her iki akışkan kompozit de benzer şekilde başarılı klinik sonuçlar göstermiştir. Dolayısıyla, diş ve kompozit arasında ayrılmaya neden olacak bir stres oluşmadığı söylenilebilir. Ek olarak, materyallerin düşük elastisite modülü adeziv arayüzde azalmış strese neden olmuş olabilir.6,24 Zamanla, kenar aralıklarının artma intimali olmasına rağmen, bir çalışmada nemli ortamda zaman geçtikçe polimerizasyon büzülmesinin azalacağı gösterilmiştir. ${ }^{25}$ Klinik başka bir çalışmada da yüksek oranda doldurucu içeren akışkan kompozitlerin geleneksel kompozitlerde benzer sonuçlar gösterdiğini rapor etmiştir. ${ }^{23}$

Self-etch adezivlerin asiditeleri farklılık göstermektedir ve pH'ları klinik performanslarına etki edebilmektedir. Adezivlerin klinik performansı üzerine yapılmış sistematik bir derleme, hafif asidik olan iki aşamalı selfetch adezivlerin en iyi klinik performasa sahip olduğunu ve güçlü asidik self-etch adezivler $(\mathrm{pH}<1.5)$ ile iki aşamalı etch\&rinse adezivlerin ise en yetersiz sonuçları gösterdiğini belirtmiştir. ${ }^{26}$ Vertise Flow'un pH'sı 1.9'dur ve hafif asidik olarak sınıflandırılmıştır ${ }^{27}$ ancak iki restoratif materyel arasında klinik olarak anlamlı bir farklılık bulunmamaktadır. LuxaFlow akışkan kompozit rezini ile birlikte kullanılan adeziv sistem Teco, aseton içermeyen bir adezivdir. Vertise Flow'un üreticileri materyalin içine etanol bazlı bir adeziv sistem olan Optibond sistemini eklemişler ve bu şekilde kendi kendine bağlanmasını sağlamışlardır. Etch\&rinse sistemlerin daha üstün klinik sonuçlar ortaya koyması beklenirken, ${ }^{19,20}$ bu çalışmada Vertise Flow ve LuxaFlow grupları benzer klinik performans göstermiştir. Başka bir klinik çalışmada ise self-etch bir adeziv sistem ile kullanılan Vertise Flow and Premise Flowable kompozitler benzer klinik performans gösterirken her 2 kompozit de zamanla daha az alfa skoru göstermiştir. ${ }^{15}$ Bazı klinik çalışmalar ise akışkan kompozitleri fissür örtücülerle karşıllaştırmışlar ve akışkan kompozitlerin daha iyi sonuçlar gösterdiğini rapor etmişlerdir. ${ }^{10,28}$

Akışkan kompozitlerin penetrasyonu klinik başarı açısından başka bir önemli faktördür. In vitro bir çalışma, mine pürüzlendirilmesinin kendi kendine bağlanabilen kompozitlerde bağlanmayı arttırdığını ve Vertise Flow uygulanmadan önce selektif pürüzlendirme yapılmasını önermiştir. ${ }^{29}$ Küçükyılmaz ve ark. da, 24 ay sonra Vertise Flow akışkan kompozitin klinik olarak tatminkar sonuçlar ortaya koyduğunu göstermiştir ve yerleştirilen 40 adet Vertise Flow restorasyonun kenar renklenmesi açısından sadece 2 tanesinin Bravo ve bir tanesinin Çarli skoru gösterdiğini bildirmişlerdir. ${ }^{10}$

Bir ya da iki yıl gibi süreler dental materyallerin klinik performansını değerlendirmek için kısa zamanlardır. Uzun dönem çalışmalarla bu bulguları doğrulayabilmek gereklidir. Yüzeyel Sınıf I kaviteler için restorasyon seçimi kompozitlerin uzun dönem performansına bakılarak yapılmalıdır. Bu nedenle akışkan kompozit rezinler ile yapılan restorasyonlar güvenilir sonuçlar açısından periyodik olarak takip edilmelidir.

\section{SONUÇ}

Bu klinik çalışmada, yüzeysel Sınıf I kavitelerde kendi kendine bağlanabilen bir akışkan kompozit rezinin, etch\&rinse adeziv system ile birlikte kullanılan geleneksel bir akışkan kompozit rezin ile 4 yılın sonunda benzer klinik performans gösterdiği görülmüştür. Ancak her iki materyal de zamanla kenar uyumu açısından bozulmalar göstermiştir. 


\section{KAYNAKLAR}

1. Feigal RJ. Sealants and preventive restorations: review of effectiveness and clinical changes for improvement. Pediatr Dent 1998; 20(2): 85-92.

2. Gilpatrick RO, Ross JA, Simonsen RJ. Resin-toenamel bond strengths with various etching times. Quintessence Int 1991; 22(1): 47-9.

3. Ripa LW. Occlusal sealants: rationale and review of clinical trials. Int Dent J 1980;30(2):127-39.

4. Amin HE. Clinical and antibacterial effectiveness of three different sealant materials. J Dent Hyg 2008; 82(5): 45-8.

5. Dukic W, Dukic OL, Milardovic S, Vindakijevic Z. Clinical comparison of flowable composite to other fissure sealing materials--a 12 months study. Coll Antropol 2007; 31(4): 1019-24.

6. Kubo S, Yokota H, Yokota H, Hayashi Y. Three-year clinical evaluation of a flowable and a hybrid resin composite in non-carious cervical lesions. J Dent 2010; 38(3): 191-200.

7. Ryou DB, Park HS, Kim KH, Kwon TY. Use of flowable composites for orthodontic bracket bonding. Angle Orthod 2008; 78(6): 1105-9.

8. Baroudi K, Rodrigues JC. Flowable Resin Composites: A systematic review and clinical considerations. J Clin Diagn Res 2015; 9(6): ZE1824.

9. Sabbagh J, Ryelandt L, Bacherius L, Biebuyck JJ, Vreven J, Lambrechts $P$, et al. Characterization of the inorganic fraction of resin composites. J Oral Rehabil 2004; 31(11): 1090-101.

10. Kucukyilmaz E, Savas S. Evaluation of Different Fissure Sealant Materials and Flowable Composites Used as Pit-and-fissure Sealants: A 24-Month Clinical Trial. Pediatr Dent 2015; 37(5): 468-73.

11. Vichi A, Margvelashvili M, Goracci C, Papacchini F, Ferrari M. Bonding and sealing ability of a new selfadhering flowable composite resin in class I restorations. Clin Oral Investig 2013;17(6):1497-506.

12. Loguercio $A D$, de Paula $E A$, Hass $V$, Luque-Martinez I, Reis A, Perdigao J. A new universal simplified adhesive: 36-Month randomized double-blind clinical trial. J Dent 2015; 43(9): 1083-92.

13. Loguercio AD, Manica D, Ferneda F, Zander-Grande C, Amaral R, Stanislawczuk R, et al. A randomized clinical evaluation of a one- and two-step self-etch adhesive over 24 months. Oper Dent 2010; 35(3): 265-72.

14.Perdigao J, Kose C, Mena-Serrano AP, De Paula EA, Tay LY, Reis A, et al. A new universal simplified adhesive: 18-month clinical evaluation. Oper Dent 2014;39(2):113-27.

15.Sabbagh J, Dagher S, El Osta N, Souhaid P. Randomized clinical trial of a self-adhering flowable composite for class I restorations: 2-year results. Int J Dent 2017; 2017: 50-4.
16.A. Vichi CG, and M. Ferrari. Clinical study of the self-adhering flowable composite resin Vertise Flow in Class I restorations: six-month follow-up. Int Dent 2010; 12(1): 14-23.

17. Kitasako Y, Sadr A, Burrow MF, Tagami J. Thirtysix month clinical evaluation of a highly filled flowable composite for direct posterior restorations. Aust Dent J 2016; 61 (3): 366-73.

18. Wei YJ, Silikas N, Zhang ZT, Watts DC. Hygroscopic dimensional changes of selfadhering and new resin-matrix composites during water sorption/desorption cycles. Dent Mater 2011; 27(3): 259-66.

19. Loguercio AD, Bittencourt DD, Baratieri LN, Reis A. A 36-month evaluation of self-etch and etch-andrinse adhesives in noncarious cervical lesions. $J$ Am Dent Assoc 2007; 138(4): 507-14.

20.Moosavi H, Kimyai S, Forghani M, Khodadadi R. The clinical effectiveness of various adhesive systems: an 18-month evaluation. Oper Dent 2013; 38(2): 134-41.

21.Perdigao J, Dutra-Correa $\mathrm{M}$, Saraceni $\mathrm{CH}$, Ciaramicoli MT, Kiyan VH, Queiroz CS. Randomized clinical trial of four adhesion strategies: 18-month results. Oper Dent 2012; 37(1): 3-11.

22. Labella R, Lambrechts $P$, Van Meerbeek B, Vanherle G. Polymerization shrinkage and elasticity of flowable composites and filled adhesives. Dent Mater 1999; 15(2): 128-37.

23. Lawson NC, Radhakrishnan R, Givan DA, Ramp LC, Burgess JO. Two-year randomized, controlled clinical trial of a flowable and conventional composite in class I restorations. Oper Dent 2015;40(6): 594-602.

24. Rocha Gomes Torres C, Rego HM, Perote LC, Santos LF, Kamozaki MB, Gutierrez NC, et al. A split-mouth randomized clinical trial of conventional and heavy flowable composites in class II restorations. J Dent 2014; 42(7): 793-9.

25.25. Park JW, Ferracane JL. Water aging reverses residual stresses in hydrophilic dental composites. J Dent Res 2014; 93(2): 195-200.

26. Peumans M, Kanumilli P, De Munck J, Van Landuyt $K$, Lambrechts $P$, Van Meerbeek B. Clinical effectiveness of contemporary adhesives: a systematic review of current clinical trials. Dent Mater 2005; 21 (9): 864-81.

27. Moura SK, Pelizzaro A, Dal Bianco K, de Goes MF, Loguercio AD, Reis A, et al. Does the acidity of selfetching primers affect bond strength and surface morphology of enamel? J Adhes Dent 2006; 8(2): 75-83. 
28.Corona SA, Borsatto MC, Garcia L, Ramos RP, PalmaDibb RG. Randomized, controlled trial comparing the retention of a flowable restorative system with a conventional resin sealant: one-year follow up. Int $\mathrm{J}$ Paediatr Dent 2005; 15(1): 44-50.

29.29. Eliades A, Birpou E, Eliades T, Eliades G. Selfadhesive restoratives as pit and fissure sealants: a comparative laboratory study. Dent Mater 2013; 29(7): 752-62.

Yazışma Adresi:

Fatma Dilşad ÖZ

Hacettepe Üniversitesi

Diş Hekimliği Fakültesi

Restoratif Diş Tedavisi AD

0610, Sinhiye, Ankara, Türkiye

Tel : +90312305 2270

Faks : +903123113438

E Posta: dilsadoz@yahoo.com 